\title{
О.А. Скоркин
}

\section{Значимость гуманитарной компоненты образования в технических вузах}

\begin{abstract}
Аннотаиия. В условиях радикального увеличения потоков информации меняется механизм переработки и осознания, как существенная часть образования, которая следует за изменяющимися реалиями общества. Идеология образования, установка на единые общие задачи, управляемая государством как заказчиком на этапах получения среднего и высшего образования отражает значимость гуманитарных составляющих организованного обучения. Гуманитарные науки - это не только приобщение к достижениям человеческой культуры, это и смысловое ядро образования, и культура мышиления. Автор аргументировано отражает в статье значимость гуманитарных и мировоззренческих дисциплин (в частности, астрономии в школе, философии и обществоведческих дисииплин в вузах физико-математической и технической ориентации), и ставит ряд проблем метауровня по отношению к текущим преобразованиям в системе отечественного образования. Отсутствие политической воли в обеспечении этого метауровня лишает значимых достоинств получаемого образования - стать личностью, стать достойным гражданином своего отечества.

Ключевые слова: мировоззрение, гуманитарные науки, личность, предназначение, антропология, культурология, социум, информационные технологии, современность.
\end{abstract}

$\mathrm{T}$ ермин «образование»используется и применительно к конечному или промежуточному продукту, и к процессу его достижения. В данном случае образование понимается как процесс, с которым каждый из нас связан всю свою жизнь, от рождения до ухода в иной мир, впрочем так же, как и с собственным здоровьем. И отношение к нему схожее, разве что в медицине иногда имеет место хирургическое вмешательство, результаты которого мы очень скоро осознаем, а применительно к образованию наивно полагать, что некие революционные акты дадут быстрый ожидаемый эффект.

\section{Всё течет, всё изменяется}

При этом, в чем суть образования трактуется по-разному и на наивный вопрос (а зачем оно, образование, необходимо, разве недостаточно здравого смысла) ответить непросто - вариантов ответов очень много, они справедливы, не вызывают возражений, но не всеохватны, носят частный характер или только касаются проблем, связанных опять же с образованием. «Главная цель образования в процессе социализации личности - научить человека жить в обществе, достигать гармонии в отношениях с другими людьми и самим собой, умению находить устойчивость в неустойчивом социальном пространстве и тем самым реализовывать свою индивидуальность». Образование «является важнейшим способом трансляции культурного опыта новым поколениям, сохраняющим социум как таковой, и одновременно насыщает сознание человека, делая его в определенной мере обладателем общественного богатства. В образовании интересы человека и общества совпадают: общество помогает человеку увеличить свой потенциал, повысить значимость, а человек одновременно вливает свой творческий потенциал в становление и развитие самого социума» ${ }^{2}$. «Образование - это не учебная подготовка к профессии, специальности, ко всякого рода производительности, и тем более образование существует не ради такой подготовки, наоборот, всякая учебная подготовка к чему-то существует для образования» ${ }^{3}$ «Различный тип культуры формирует различный тип личности, либо ориентированный на приоритет личностно-индивидуальных

\footnotetext{
${ }^{1}$ Морозов В.В. Образование как процесс социализации личности // Философия и культура. 2012. № 3 (51). С. 94.

2 Ярославцева Е.И. Самореализация личности в системе социальных отношений. М.: Изд-во МГУ, 2012. С. 130.

${ }^{3}$ Шелер М. Формы знания и образования. М.: Гнозис, 1994. C. 31-32.
} 
ценностей, либо на приобщение к общественным нормам» ${ }^{4}$. «Образование - это важнейший инструмент выработки и реализации новой социальной идеологии, идеологии гуманизма, демократии и социальной справедливости» ${ }^{5}$ Образование - это погружение в мир культуры. «Культура - это не знания, технологии, ценности, нормы и материальные предметы, а то, что выражается при помощи этих знаний, технологий, ценностей, норм и т.д., а также то, что лежит в основе их создания (конструирования) и воспроизводства» ${ }^{6}$.

Образованный человек вовсе не непременно счастливый или удачливый, или привлекательный в общении, его вечно сопровождают сложности по работе или в личной жизни, управлять им крайне сложно, богатства образование не прибавляет. И тем не менее с образованным человеком заведомо интересней общаться, сквозь призму его мировосприятия острей и ярче воспринимаешь и проблемы, и красоту окружающего тебя мира, и значимость человеческой жизни.

За прошедшие 2-3 десятилетия в большинстве развитых стран поток информации, пронизывающий обывателя, увеличился более, чем на порядок, изменилась социальная среда, общество стало постиндустриальным, информационным. Информация с каждым годом становится все большей ценностью, ресурсом развития, объединяющей средой, доминантой общественной жизни и существования человека. С изменением характера современного общества происходит также изменение требований к образованиюв целом, образование следует или должно следовать за изменяющимися реалиями цивилизованного общества. Современная эпоха диктует необходимость глубинных изменений системы образования. Переход от техногенной к антропогенной цивилизации сопровождается пересмотром привычных представлений о человеке, о мире, сменой ценностных ориентаций. Прежде всего, меняется основная образовательная цель, которая теперь заключается не столько в знаниевой подготовке,

\footnotetext{
${ }^{4}$ Морозов В.В. Образование как процесс социализации личности // Философия и культура. 2012. № 3 (51). С. 87.

${ }^{5}$ Днепров Э.Д. Новейшая политическая история российского образования: опыт и уроки. М.: Мариос, 2011. С. 36.

${ }^{6}$ Теория культуры. Разнообразие подходов и возможности их интеграции / Под. ред. Ю.М. Резника. М.: Научно-политическая книга, 2012. С. 40.
}

сколько в обеспечении условий для самоопределения и самореализации личности, - научить понимать мир, общество, себя, свое дело. Переход к информационному обществу требует глубоких изменений в деятельности по производству знаний и по их передачи и усвоению, и, как следствие, принципиально изменяет роль и значимость образования.

Это утверждение базируется на изменении отношения и к человеку, и к знанию, которое должно быть обращено в будущее, а не в прошлое. Критерием реализации новой образовательной модели становится опережающее отражение или степень «познания будущего». В новой образовательной парадигме обучающийся становится субъектом познавательной деятельности, а не объектом педагогического воздействия. Роль образования здесь очевидна - оно как раз и является той единственной сферой, в которой осуществляется приобретение человеком знаний и умений, обеспечивающих его полноценное существование в окружающем природном и социальном мире. Образование становится не обучением определенным знаниям и навыкам, а процессом формирования субъекта культуры. Современный человек должен не только обладать неким объемом знаний, но и уметь учиться: искать и находить необходимую информацию, чтобы решать те или иные проблемы, использовать разнообразные источники информации для решения этих проблем, постоянно приобретать дополнительные знания. Современная концепция образования предполагает формирование новых ценностей образования, которые определяются в первую очередь потребностями субъекта образования. Образовательный процесс сопровождает субъекта на всем протяжении процесса социализации, образовательные институты выступают лишь как трансляторы культурных ценностей и норм.

\section{Заказчик образования - государство}

Не следует забывать о том, сколь велика лепта, вносимая в образование семьей и улицей, а также СМИ и учитывать разнообразие воздействия и неопределенность результатов этого воздействия. Это необозримая сфера, требующая отдельного аналитического рассмотрения. Здесь не об этом речь. Управляемой, программируемой частью образования является то, которое институализировано, имеется ввиду средняя школа и вуз (разу- 


\section{Педагогика и просвещение 4(12) • 2013}

меется и все их модификации - лицеи, гимназии, университеты, их филиалы), все то, что завешается государственным документом, аттестатом или дипломом. Образование в школе, вузе является политизируемой компонентой нашей жизни, ибо потребителем его, заказчиком является государство с его идеологией, то бишь установкой на единые общие задачи. Осмысление таких единых общих задач, сущностных и глубинных целей образования и его содержания во все времена было и остается доминантой образовательного процесса. Вместе с тем очевидно, что без уяснения главных целей образования, обеспечить решение частных задач, в том числе его нормального содержания, невозможно. Например, чем обоснован набор учебных дисциплин? Как определяется объем изучения по предметам?

А что, собственно, нам ведомо про современное образование? То, что его получение строго ограничено утвержденным «сверху» бюджетом времени; что жить и творить в наших школах и вузах следует по государственному стандарту; что конечный уровень подготовки специалиста определяется не его знаниями и умениями, а наличием диплома (для трудоустройства - лучше государственного образца); что цели и содержание образования диктуются не потенциальным работодателемзаказчиком, а чиновниками из государственных органов управления; и пр.

Государство болеет, от избытка реформ устали и обучающие, и обучаемые, консервативность системы образования в таком случае выручает. Принцип Гиппократа Primum non nocere (прежде всего не навреди) в большей мере, чем врачебным, воспринят педагогическим корпусом. Сложности образования действительно информационно перенасыщенного периода переведены в другую плоскость, как учиться и отчитываться честно. Только практика ЕГЭ чего стоит. А заявление Министра образования и науки, что он покинет свой пост, как это уже сделал его подчиненный, когда у него возникнет ощущение, что он больше не сможет эффективно работать. Откуда такое барство? И почему дикой кажется мысль приоритета специалиста, педагога относительно мнения обслуживающего персонала, каковым является и Министерство образования, и порожденное им организационное обслуживание в форме региональных управлений и администрации образовательных учреждений. Что, как не болезнь государства, нужно восприни- мать в таком зазеркальи системы образования? Современная педагогическая практика все чаще сталкивается с проблемами отчужденности учеников от образования. Учащиеся оказываются за «бортом» учебного процесса и понимания роли образования и значения учения в своей жизни. Не этим ли объясняется неприятие школы как таковой? Зинна «Ненавижу школу» - аргументированный крик души не только ученика, но и учителя. Не этим ли объясняется жульничанье на ЕГЭ, купленные зачеты и экзамены в вузах, халтурные диссертации? Вот уж проблемы государственного уровня. Целая цепочка проблем, порождающая следующие цепочки. Так что Министр образования и науки обречен развлекаться порожденными психологическими играми, пока позволит здоровье. Давно пора вернуться к исходным проблемам, не тем, что поставлены с ног на голову.

Первое. Государственные образовательные стандарты по своей сути это опосредованная форма цели (или целей) образования. В самой мягкой формулировке «их существующая форма не только нарушает принципы автономности и академической свободы в образовании, но и ограничивает творчество педагога и ученика»7. Проблема целей и содержания образования и решение вопросов должно иметь приоритетное значение среди важнейших социально-политических задач государства. Можно сказать, политическое будущее любой страны стратегически определяется будущим системы образования. «В дебатах об образовании пока слишком много сиюминутной реакции (на Болонскую реформу, на законопроект о реформе высшего образования, на ЕГЭ) и мало осознания метаморфоз, произошедших со знанием в его отношению к человеку, производству, потреблению, обществу в целом» ${ }^{8}$. Определиться в целях в данном случае это и ответ на вопрос, с каким багажом знаний с какими данными можно обучаться в вузе.

Второе. Пора приобрести ясность с системой оценивания - оценки успеваемости в школе, экзаменационные в вузе. Насколько они необхо-

\footnotetext{
${ }^{7}$ Скворцов Л.В. Информационная культура и проблема метаобразования // Культурология: Дайджест. М.: ИНИОН PAH, 1999. № 3.236 c.

${ }^{8}$ Маяцкий М. Университет называется // Логос. 2013. № 1 (91). C. 9.
} 
димы и надо ли их связывать с экономическими регуляторами?

Третье. Обязательность мировоззренческих и гуманитарных дисциплин. Остановимся на этом вопросе подробней. Гуманитарное знание, это знание ценностно-смысловое, пристрастное, осмысленное. Смысл составляет содержательное «ядро» гуманитарного знания. Категория смысла очень подробно раскрыта во многих исследованиях ${ }^{9}$. В. Франкл называет его «высшей интегрирующей инстанцией личности» ${ }^{10}$.

\section{Значимость гуманитарных дисциплин}

Гуманитарное знание включает в себя ценностное отношение к изучаемой действительности; объект познания оценивается с позиций нравственных, культурных, религиозных, эстетических и т.п. Содержание гуманитарного знания связано с вопросами смысла человеческого существования; оно «предполагает переход от факта к смыслу, от вещи к ценности, от объяснения к пониманию. Гуманитарное познание представляет собой ценностно-смысловое освоение человеческого бытия. Прибегать к ценностным оценкам явлений природы бессмысленно, так как вещи и явления природы не добры и не злы. Гуманитарное знание - это единство истины и ценности, факта и смысла, сущего и должного» ${ }^{11}$.

Именно гуманитарное знание, которое включает в себя смыслы и отношение, способно наполнять личность качествами и потребностями, отражающими субъективное Я. Любая учебная деятельность ученика на уроке, студента на лекции или в лаборатории должна быть наполнена смыслами и пониманием того, что я делаю. Неважно, урок ли это математики или пения, любая деятельность на занятиях должна носить личный смысл, мотив, анализ своих поступков и действий. Безличностные знания (как и информация) становятся значимыми, когда обретают смысл и значение именно для меня. И работая не

\footnotetext{
${ }^{9}$ Громыко Н. Интернет, постмодернизм и современное образование // Кентавр. 2001. № 27; Карпенко М.П. О проблеме измерения знаний в обучении // Школьные технологии. 1998. № 4. С. 173-175.

${ }^{10}$ Франкл В. Человек в поисках смысла. М., 1990.

${ }^{11}$ Скворцов Л.В. Информационная культура и проблема метаобразования // Культурология: Дайджест. М.: ИНИОН PAH, 1999. № 3. C. 88.
}

с безличной информацией, а с гуманитарным знанием, субъект обретает смысл своей деятельности и понимание себя в конкретной ситуации.

В гуманитарной парадигме, формировавшейся по мере стремления человечества в социокультурном развитии проникнуть в глубины субъективного мира, основой профессионально-педагогической ценностью становится конкретный человек, его внутреннее пространство, специфика индивидуального процесса познания. Гуманитарное познание ориентировано на индивидуальность, обращено к духовному миру человека, кего личной системе ценностей и смыслу своей жизни.

Обогащается личностный опыт обучаемого как опыт субъективной реальности за счет диалога с природой, с самим собой, с объектами собственной деятельности, с другими людьми. Детерминация развития человека указывает на невозможность человеческой жизнедеятельности без такого рода взаимодействия, многочисленные отношения обусловливают степень его человекосообразности, гуманитарное качество личности ${ }^{12}$.

Это заставляет шире взглянуть на образование, как на социальный институт, через который осуществляется передача культурного наследия региона, страны от поколения к поколению. С развернутым представлением взаимосвязи образования и культуры можно ознакомиться, к примеру, в работах ${ }^{13}$. Эта важная и тонкая проблема неслучайно обсуждается практически на всех ставших регулярными Международных конференциях «Информационные технологии в образовании» (относительно среднего образования) и Международных научных конференциях «Высшее образование для XXI века».

Таким образом, именно гуманитарное знание, которое включает в себя смыслы и отношение, способно наполнять личность качествами и потребностями, отражающими субъективное Я. Любая учебная деятельность ученика на уроке, должна быть наполнена смыслами и пониманием того, что я делаю. Неважно, урок, ли это математики

\footnotetext{
${ }^{12}$ Слободчиков В.И., Исаев Е.И. Основы психологической антропологии. Психология человека: Введение в психологию субъектности: Учебное пособие для вузов. М.: ШколаПресс, 1995.

${ }^{13}$ Гуревич П.С. Психология и педагогика. М.: Юрайт, 2013; Пелипенко А.А. Постижение культуры. Часть 1. Культура и смысл. М.: РОССПЭН, 2013.
} 


\section{Педагогика и просвещение 4(12) • 2013}

или пения, любая деятельность на уроке ученика должна носить личный смысл, мотив, анализ своих поступков и действий. Безличностные знания (информация) становятся значимыми, когда обретают смысл и значение именно для меня. И работая на уроке не с безличной информацией, а с гуманитарным знанием, субъект обретает смысл своей деятельности и понимание себя в конкретной ситуации.

Похоже на то, что этот последний, третий комплекс проблем вполне разрешим и частично снимает напряженность первого комплекса, и, кроме того, остро стоит на факультетах или в вузах физико-математических и естественнонаучной ориентации, то есть технического толка. В технических вузах общее падение уровня образования. Вроде бы естественно желание поднять уровень образования за счет исключения «ненужных для специальности предметов». Какой прок для ультрановационной специальности от философии, истории мысли, этики, эстетики? Неудивительно было в одной из телевизионных передач услышать от ректора одного из ведущих вузов страны: «И вообще гуманитарные науки - это напрасно затраченные иллюзии». Понять такую сентенцию непросто, однако угадать с двух раз - чего здесь больше косноязычия или профессионального кретинизма - не удастся, очень уж корявая фраза. По-видимому имелось ввиду - напрасно потерянное время. Стоит ли при этом удивляться языку, на котором общаются профессионалы сферы IT разлива последнего десятилетия прошлого или первого десятилетия нынешнего века? А к чему сводятся попытки людей другой профессии (медика, юриста, литературоведа, математика) понять, чем они занимаются. А чего стоит откровенный наезд государственной машины на гуманитарные науки и учреждения? Слияние санкт-петербургского Института истории искусств или московского института культурологии с «кем-то» или «чемто», выселение на восьмом десятке лет Института философии РАН, отмена аспирантского экзамена по философии, список длинный.

А на чем держится потребность в гуманитарных науках, которые не профильны для данного вуза или факультета вуза? Во-первых, статус государственного университета заставляет заботиться о достаточно широком (включая и гуманитаристику) образовании, которое способс- твует, так или иначе, наращиванию духовного потенциала личности. Во-вторых, подготовка кадров, ориентированных на исследования и разработки, предполагает достаточно гармоничное развитие будущего специалиста, формирование не только аналитических («строгое математически мышление»), но и синтетических («продуктивное воображение») способностей, сопряжения левого и правого полушарий. В-третьих, профессиональная деятельность инженера осуществляется в определенном социальном (институциональном, рыночном, правовом, межличностном и т.д.) контексте, значимость которого в технологии этой деятельности неуклонно возрастает, благодаря, в первую очередь и главным образом, происходящему в наши дни переходу к инновациям, требующим разноаспектных взглядов. В этом ряду - знания и верования; цели, смыслы и идеалы; национальные традиции и общечеловеческие ценности; технические устройства и феномены искусства; этические, юридические, административные и прочие нормы, правила и процедуры социальных взаимодействий; институты и организации; требования государства и запросы рынка; налоги, финансы и бизнес и многое другое. Рассмотрение, скажем, не только форм, способов и приемов конструирования научно-инженерного замысла («проекта»), но и социальных факторов, обеспечивающих его превращение в техническое изделие, востребованное и обществом, и государством, и конкурентным рынком. Именно благодаря такой востребованности новшество (изобретение, усовершенствование и т.д.) обретает свойство инновации.

Разумеется, постсоветский период принес множество положительных и рациональных изменений. Произошел радикальный сдвиг в преподавании всего цикла обществоведческих дисциплин. Главное - преодолена их заидеологизированность. Состоялась их более или менее последовательная гуманитаризация, обобщающий смысл которой - выход к общечеловеческим ценностям и вековым российским традициям. Утвердился рационально сбалансированный, свободный от демагогии и опирающийся на доказательства стиль рассмотрения реальных обществоведческих проблем. Приходится сожалеть, что существенно сокращен их объем и, как следствие, нарушен принцип непрерывности. При образовавшемся «лоскутном одеяле» теряется мировоззренческая цельность. 
Гуманитаризация инженерного образования

Гуманитаризация инженерного образования - проблема многоаспектная. Определение состава, объема, последовательности, способов и методик ввода гуманитарного знания в технологию инженерного образования - дело и чрезвычайно ответственное, и весьма непростое. Уменьшение объемов требует соответствующих методик и учебников. А даже подготовленные учебно-методические рекомендации по тем или иным гуманитарным проблемам могут быть представленными лишь в бумажном формате, в виде единичных экземпляров, то есть кардинально ограничены для массового пользования. Осуществить на практике должную компьютеризацию учебнопедагогического процесса можно при условии, что все преподаватели более или менее владеют соответствующими умениями и навыками. Но с этим-то как раз дело обстоит не совсем, мягко говоря, хорошо. В достаточной мере компетентных - считанные единицы. Соответственно - не только важен, но и крайне необходим компьютерный всеобуч хотя бы, для начала, для представления учебно-методических материалов в электронном формате. И кто же заинтересован в таких хлопотах?

Болонское соглашение подарило нам букет проблем, связанных с бакалавриатом. Исходная и самая серьезная проблема - в какой мере система гуманитарной и фундаментальной подготовки специалистов совместима с бакалавриатом, насколько она отвечает его запросам. Это две кардинально различные стратегии. И у той, и у другой есть свои и плюсы, и минусы. С каждой из них связаны свои и надежды, и страхи, непрерывно подогреваемые заботой о трудоустройстве бакалавров, их востребованности на рынке труда.

В границах «прагматической» установки бакалавриат представляется укороченным по времени и максимально упрощенным вариантом формирования специалиста. Его выстраивание, соответственно, достигается ценой предельной минимизации (вплоть до обнуления, если, в особенности, нет защищенности федеральными стандартами) всего того, что служит его общему развитию. Речь идет о гуманитарном знании, в первую очередь, и о некоторой избыточной теоретико-математической подготовке, во вторую. Это первые кандидаты на сокращение.
Запросы инновационной экономики к высшей инженерной школе в полной мере могут реализоваться в том и только в том случае, если бакалавриат выстраивается согласно «развивающей» стратегии, ориентированной на наращивание интеллектуального, духовного, творческого потенциала будущего выпускника. Заведомо неразумно было бы экономить на том, что составляет духовное, интеллектуальное и, разумеется, творческое ядро его будущей инновационной деятельности, непременный базис его профессионального долголетия, эпицентром которого становится формирование культуры мышления.

Мне представляется, что будущее за «развивающей» стратегией, за дополнительными разделами фундаментальных наук и за обществоведческими курсами, предлагаемыми студентам, а затем и школьникам в порядке их свободного выбора. Ключевым моментом идеологии перехода - понимание двух кардинально различных моделей, двух культур обучения. В первом (условно советском) случае - это выстраивание процесса обучения в директивном порядке, с помощью массы принуждающих и контролирующих инструментов. Во втором, (американо-европейском) случае - «рыночная модель», «купля-продажа» образовательных услуг («продуктов») в границах учебного заведения. Это обстоятельство - мощный стимул развития и самоутверждения обучаемого. Он избирательно, исходя из личностных предпочтений присваивает («покупает») те и именно те образовательные услуги (в виде так называемых «кредитов»), которые позволят быть по окончании учебного заведения успешным «продавцом» собственных профессиональных знаний, умений и навыков на конкурентном рынке труда.

Освоение знания, безусловно, способствует раскрепощению интеллекта, расширению пространства свободы, самоответственного выбора, личностной инициативы, формированию того, что можно назвать «дерзновением ума». Естественнонаучное и гуманитарное знание выступают в качестве своего рода «alter Ego», которые лишь совместно, одновременно и исключая и дополняя друг друга, в состоянии обеспечить достаточно гармоничное развитие способностей человека. И это относится и к средней, и к высшей школе. 


\section{Педагогика и просвещение 4(12) • 2013}

\section{Резюме}

Изменились реалии общества. Радикальное увеличение потоков информации изменило механизм ее осознания и переработки. Образование становится не обучением определенным знаниям и навыкам, а процессом формирования субъекта культуры. Меняются ценности образования, понятие знания насыщается другим смыслом.

Гуманитарные науки - это приобщение к культуре, это смысловое ядро образования, это и культура мышления. Пренебрежение ими - путь к профессиональному кретинизму. Значимость гуманитарной части образования с необходимостью растет.
И школа, и бакалавриат, и магистратура должны выстраиваться согласно «развивающей» стратегии, ориентированной на наращивание интеллектуального, духовного, творческого потенциала выпускника. Обеспечением активного участия в «развивающем» образовании является свободный выбор из мировоззренческих и гуманитарных дисциплин. Наиболее запутанной, проблемной является гуманитарное образование бакалавриата в вузах технических и физико-математического направления. Для этого требуется предварительно решить вопрос непрерывного гуманитарного образования в магистратуре и, в первую очередь, философии как учебной дисциплины.

\section{Список литературы:}

1. Громыко Н. Интернет, постмодернизм и современное образование // Кентавр. 2001. № 27.

2. Гуревич П.С. Психология и педагогика. М.: Юрайт, 2013.

3. Днепров Э.Д. Новейшая политическая история российского образования: опыт и уроки. М.: Мариос, 2011.

4. Егорова И.В. Качество образования как проблема // Педагогика и просвещение. 2013. № 1. С. 72-78.

5. Карпенко М.П. О проблеме измерения знаний в обучении // Школьные технологии. 1998. № 4. С. 173-175.

6. Маяцкий М. Университет называется // Логос. 2013. № 1 (91).

7. Морозов В.В. Образование как процесс социализации личности // Философия и культура. 2012. №3(51). С. 85-94.

8. Пелипенко А.А. Постижение культуры. Часть 1. Культура и смысл. М.: РОССПЭН, 2013.

9. Сиземская И.Н. Проблемы образования в контексте отечественного философско-педагогического наследия // Педагогика и просвещение. 2012. № 3. С. 7-15.

10. Скворцов Л.В. Информационная культура и проблема метаобразования // Культурология: Дайджест. М.: ИНИОН РАН, 1999. № 3. 236 с.

11. Слободчиков В.И., Исаев Е.И. Основы психологической антропологи и. Психология человека: Введение в психологию субъектности: Учебное пособие для вузов. М.: Школа-Пресс, 1995.

12. Теория культуры. Разнообразие подходов и возможности их интеграции / Под ред. Ю.М. Резника. М.: Научно-политическая книга, 2012.

13. Франкл В. Человек в поисках смысла. М., 1990.

14. Шелер М. Формы знания и образования. М.: Гнозис, 1994.

15. Ярославцева Е.И. Самореализация личности в системе социальных отношений. М.: Изд. МГУ, 2012.

\section{References (transliteration):}

1. Gromyko N. Internet, postmodernizm i sovremennoe obrazovanie // Kentavr. 2001. № 27.

2. Gurevich P.S. Psikhologiya i pedagogika. M.: Yurait, 2013.

3. Dneprov E.D. Noveishaya politicheskaya istoriya rossiiskogo obrazovaniya: opyt i uroki. M.: Marios, 2011.

4. Egorova I.V. Kachestvo obrazovaniya kak problema // Pedagogika i prosveshchenie. 2013. № 1. C. $72-78$.

5. Karpenko M.P. O probleme izmereniya znanii v obuchenii // Shkol'nye tekhnologii. 1998. № 4. S. 173-175.

6. Mayatskii M. Universitet nazyvaetsya // Logos. 2013. № 1 (91). 


\section{Образование}

7. Morozov V.V. Obrazovanie kak protsess sotsializatsii lichnosti // Filosofiya i kul'tura. 2012. № 3 (51). S. 85-94.

8. Pelipenko A.A. Postizhenie kul'tury. Chast' 1. Kul'tura i smysl. M.: ROSSPEN, 2013.

9. Sizemskaya I.N. Problemy obrazovaniya v kontekste otechestvennogo filosofsko-pedagogicheskogo naslediya // Pedagogika i prosveshchenie. 2012. № 3. C. 7-15.

10. Skvortsov L.V. Informatsionnaya kul'tura i problema metaobrazovaniya // Kul'turologiya: Daidzhest. M.: INION RAN, 1999. № 3. 236 s.

11. Slobodchikov V.I., Isaev E.I. Osnovy psikhologicheskoi antropologii. Psikhologiya cheloveka: Vvedenie v psikhologiyu sub"ektnosti: Uchebnoe posobie dlya vuzov. M.: Shkola-Press, 1995.

12. Teoriya kul'tury. Raznoobrazie podkhodov i vozmozhnosti ikh integratsii / Pod red. Yu.M. Reznika. M.: Nauchno-politicheskaya kniga, 2012.

13. Frankl V. Chelovek v poiskakh smysla. M., 1990.

14. Sheler M. Formy znaniya i obrazovaniya. M.: Gnozis, 1994.

15. Yaroslavtseva E.I. Samorealizatsiya lichnosti v sisteme sotsial'nykh otnoshenii. M.: Izd. MGU, 2012. 